\title{
PIEZOELEKTRIK SEBAGAI PEMANEN ENERGI DENGAN PENAMBAHAN BLUFF BODY SEGITIGA
}

\author{
Kasum \\ Program Studi Teknik Mesin \\ Sekolah Tinggi Teknologi Jakarta \\ Email: kasum@sttj.ac.id \\ Fajar Mulyana \\ Program Studi Teknik Mesin \\ Sekolah Tinggi Teknologi Jakarta \\ Email: fajar@sttj.ac.id \\ Adhes Gamayel \\ Program Studi Teknik Mesin \\ Sekolah Tinggi Teknologi Jakarta \\ Email: adhes@sttj.ac.id
}

\begin{abstract}
ABSTRAK
Piezoelektrik adalah salah satu pemanen energi yang menghasilkan energi listrik ketika mengalami defleksi. Penelitian mengenai besaran tegangan listrik akibat perbedaan penampang bluff body telah dilakukan, namun penelitian tentang potensi bluff body segitiga masih belum dilakukan. Metode penelitian adalah mengamati piezoelektrik yang bergetar dan melakukan pengukuran tegangan listrik. Bluff body yang dipasang berpenampang segitiga dengan panjang alas dan tinggi sama yaitu, $1 \mathrm{~cm}, 2 \mathrm{~cm}$, dan $3 \mathrm{~cm}$. Penelitian dilakukan di dalam terowongan angin mini dengan kecepatan angin $3 \mathrm{~m} / \mathrm{s}$ dan jarak piezoelektrik terhadap bluff body adalah $50 \mathrm{~mm}$. Hasil yang didapatkan adalah bluff body penampang segitiga $1 \mathrm{~cm}$ memiliki nilai efektif tertinggi yaitu 5,21 x $10^{-3}$ volt. Aliran udara saat melewati ujung segitiga bagian atas menyebabkan terjadi olakan lebih banyak dibandingkan saat aliran udara melewati alas segitiga. Semakin besar olakan yang terjadi maka udara yang menumbuk permukaan piezoelektrik semakin besar sehingga nilai efektifnya menjadi tinggi.
\end{abstract}

Kata kunci: piezoelektrik; panen energi; bluff body; olakan.

\begin{abstract}
Piezoelectric is one of energy harvester that produces electrical energy when deflection happens. Research on the effect of the bluff body to piezoelectric's electrical voltage has been done, but research on the potential of the triangle bluff body has not been done. This research method is to measure electrical voltage from piezoelectric with cantilever system. Bluff body is installed as a barrier is a bluff body with triangle cross section with the same a long base and height i.e: $1 \mathrm{~cm}, 2 \mathrm{~cm}$, and $3 \mathrm{~cm}$. This study was conducted using a mini wind tunnel with a wind speed of $3 \mathrm{~m} / \mathrm{s}$ and distance of piezoelectric to bluff body is $50 \mathrm{~mm}$. The result obtained is a bluff body cross-section triangle $1 \mathrm{~cm}$ has the highest effective value of $5.21 \times 10^{-3}$ volts. Airflow as it passes over the top of the upper triangle causes more vortex than the base of the triangle. The bigger vortex occurs then the bigger air strike piezoelektrik surface, so that the effective value becomes high.
\end{abstract}

Keywords: piezoelectric; energy harvesting; bluff body; vortex.

\section{PENDAHULUAN}

Piezoelektrik adalah salah satu alat pemanen energi yang menghasilkan energi listrik ketika mengalami defleksi. Polarisasi partikel penyusun piezoelektrik terjadi saat defleksi sehingga menimbulkan konsentrasi muatan listrik. Ketika terjadi defleksi secara berulang, energi listrik yang dihasilkan dapat disimpan dalam penyimpan energi listrik yaitu baterai atau konduktor. Dimensi piezoelektrik yang kecil dan tipis menyebabkan defleksi kurang maksimal sehingga energi yang dihasilkan kecil. Oleh karena itu, piezoelektrik dikategorikan sebagai pemanen energi tingkat mikro.

Salah satu sistem yang dipakai untuk membangkitkan tegangan listrik pada piezoelektrik yaitu sistem kantilever. Sistem kantilever piezoelektrik merupakan sistem dengan cara menjepit salah satu ujung piezoelektrik. Jika ujung bebas piezoelektrik diberi gaya, terjadi getaran dan piezoelektrik akan bergerak naik turun. Jika 
digambarkan, gerakan naik turun piezoelektrik akan membentuk grafik sinusoidal yang identik dengan grafik tegangan listrik bolak-balik. Telah dilakukan penelitian tentang sistem kantilever piezoelektrik dengan dan tanpa beban di ujung piezoelektrik [1]. Kantilever tanpa beban menghasilkan 4.05 volt pada frekuensi $108.13 \mathrm{~Hz}$. Sebaliknya, dihasilkan tegangan 13,35 V pada frekuensi $125,5 \mathrm{~Hz}$. Penelitian lain [2] mendapatkan daya sebesar 6,5 $\mathrm{mW}$ pada MEM dengan panjang $0,26 \mathrm{~mm}$ dan frekuensi $13,4 \mathrm{~Hz}$.

Penelitian tentang peningkatan tegangan listrik terus dikembangkan. Salah satunya dengan metode galloping yang didefinisikan sebagai ketidakstabilan dinamis yang mengenai struktur elastis akibat adanya aliran turbulen [3]. Galloping digunakan karena dapat menghasilkan amplitudo besar pada frekuensi yang rendah disaat angin menumbuk dengan tiba-tiba (tidak simultan) [4]. Sirohi \& Mahadik [5] menggunakan gallops berbentuk prisma dan menghasilkan $50 \mathrm{~mW}$ pada kecepatan angin 11,6 mph. Abdelkefi et al [6] menggunakan balok menghasilkan $1.7 \mathrm{~W}$ pada kecepatan angin $15 \mathrm{~m} / \mathrm{s}$. Pada weak galloping, Weinstein et al [7] menggunakan silinder dan menghasilkan 100-3000 mikrowatt pada kecepatan angin 2,5 m/s. Gamayel [8] menggunakan bluff body penampang segitiga menghasilkan tegangan listrik maksimal $0.034 \mathrm{mV}$ pada kecepatan angin $2 \mathrm{~m} / \mathrm{s}$. Dengan penampang ujung yang runcing, dimungkinkan terjadi peningkatan kecepatan saat melewati bluff body, sehingga saat ujung runcing telah terlewati, maka akan terjadi vortex (olakan).

Potensi bluff body segitiga dalam pembangkitan energi pada piezoelektrik masih jarang dilakukan. Oleh karena itu, diperlukan penelitian mengenai pengaruh perbedaan luasan segitiga terhadap potensial listrik yang dibangkitkan. Penelitian ini bertujuan untuk mempelajari konversi energi angin menjadi energi listrik dengan adanya bluff body tanpa mempertimbangkan metode penyimpanan energi listrik yang dihasilkan. Fokus bahasan pada penelitian ini terletak pada perubahan aliran udara saat melewati bluff body penampang segitiga.

\section{METODOLOGI PENELITIAN}

\subsection{Metode Penelitian}

Penelitian ini mengamati piezoelektrik dan melakukan pengukuran tegangan listrik dari piezoelektrik yang ditempatkan berjarak $50 \mathrm{~mm}$ dari bluff body berpenampang segitiga. Dari data pengukuran tersebut dapat dibuat grafik hubungan tegangan listrik terhadap waktu. Selain itu, dapat dihasilkan nilai efektif tegangan listrik dari variabel bebas yang dipakai. Variabel bebas dalam penelitian ini adalah dimensi bluff body, dimana alas dan tinggi dalam satu penampang segitiga memiliki ukuran yang sama. Dimensi bluff body yang dipakai adalah $1 \mathrm{~cm}, 2 \mathrm{~cm}$, dan $3 \mathrm{~cm}$. Ilustrasi bluff body dengan dimensi dan posisi piezoelektrik dapat dilihat pada gambar 1.

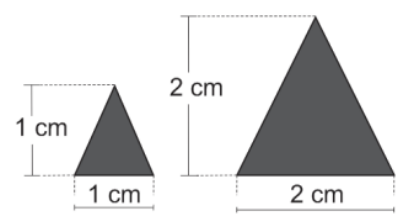

(a)

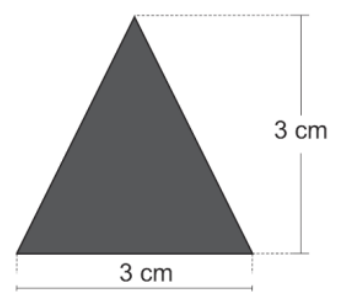

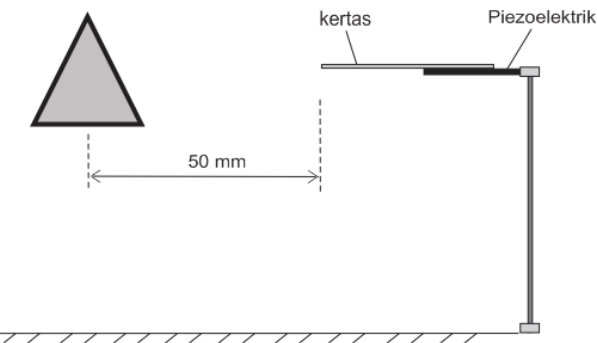

(b)

Gambar 1. (a) ukuran bluff body yang digunakan, (b) Jarak bluff body terhadap piezoelektrik

\subsection{Alat, Bahan dan Instalasi Penelitian}

Bahan piezoelektrik yang dipakai adalah jenis PVDF (polyvinylidene fluoride) tipe LDT0-028K berdimensi luas $9.8 \times 5.2 \mathrm{~mm}$, ketebalan $28 \mu \mathrm{m}$ dilapisi polyester $0.125 \mathrm{~mm}$ dan total dimensinya adalah $25 \times 15 \mathrm{~mm}$. Dibagian atas piezoelektrik ditambahkan kertas dengan dimensi 56 x $61 \mathrm{~mm}$ dengan tujuan agar lebih banyak aliran angin yang menumbuk pada area tersebut. Lebih jelasnya lihat gambar 2. 


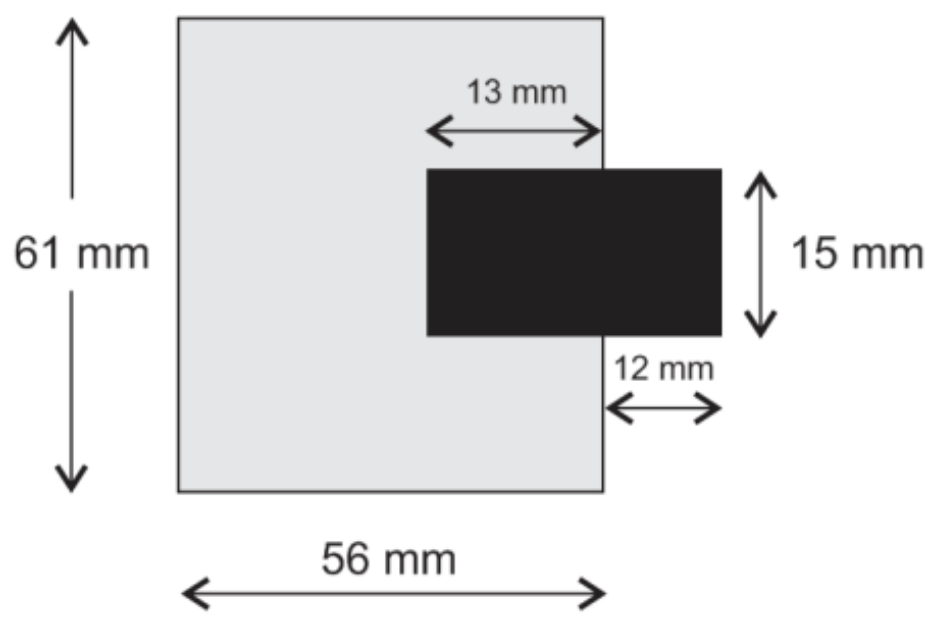

Gambar 2. Dimensi Piezoelektrik

Pengukuran tegangan listrik dilakukan dengan mikrokontroler dan pembacaan sistem akuisisi data menggunakan software Windaq. Pengukuran dilakukan selama 120 detik dan perekaman data sebanyak 100 data tiap detik. Data yang terkumpul kemudian dikonversi ke dalam format Microsoft Excel agar lebih mudah dalam pembuatan grafik. Piezoelektrik dan bluff body diletakkan pada terowongan angin dengan luasan penampang $180 \times 180 \mathrm{~mm}$ yang dilengkapi penyearah aliran dan kipas angin dengan kecepatan angin $3 \mathrm{~m} / \mathrm{s}$. Gambar instalasi penelitian ditampilkan pada gambar 3.

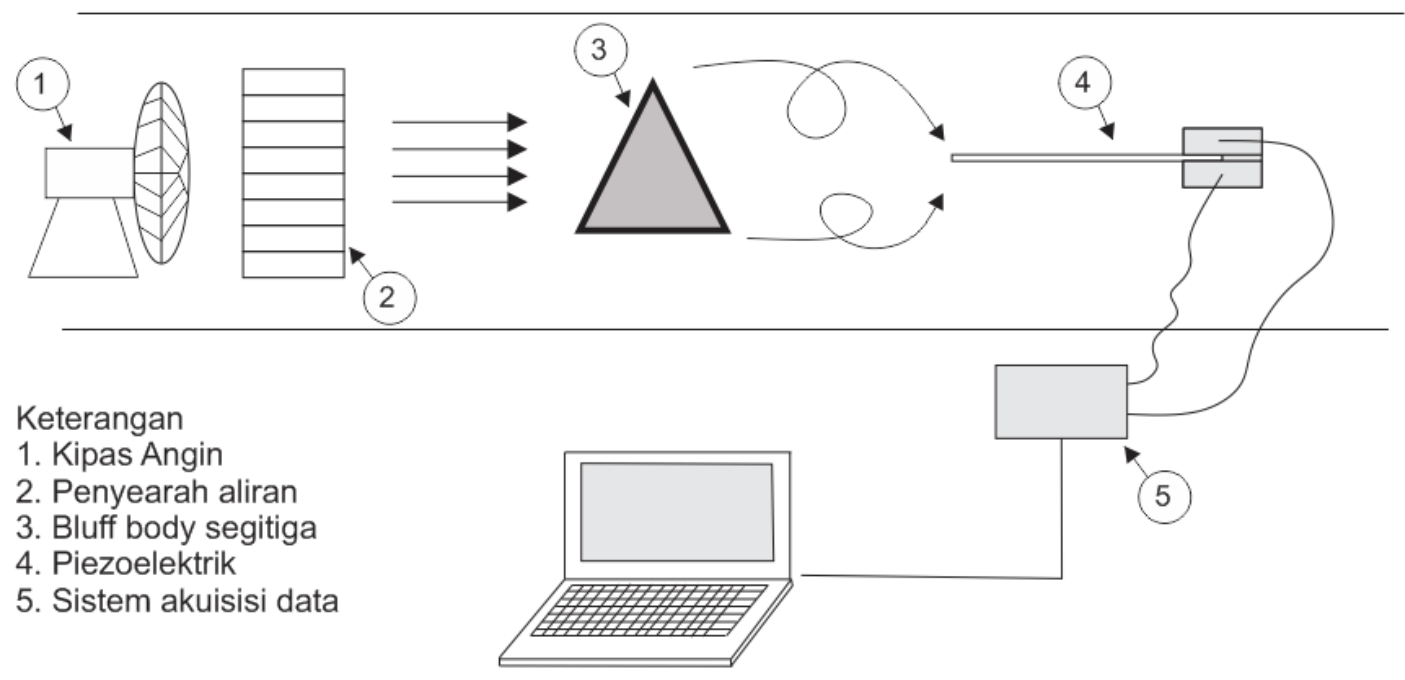

Gambar 3. Instalasi Penelitian

\section{HASIL DAN PEMBAHASAN}

Grafik hubungan tegangan listrik dan waktu dengan ukuran bluff body segitiga yang berbeda, ditampilkan pada gambar 4. Dari ketiga grafik tersebut, bluff body segitiga $3 \mathrm{~cm}$ menghasilkan tegangan listrik terkecil. Hal ini terjadi karena ukuran bluff body ini termasuk yang terbesar diantara yang diuji, sehingga dimungkinkan banyak aliran angin yang tidak menumbuk piezoelektrik. Dengan dimensi besar, maka halangan angin besar dan saat terjadi olakan pada ujung segitiga, hasil olakan tersebut sedikit yang mengenai piezoelektrik. 


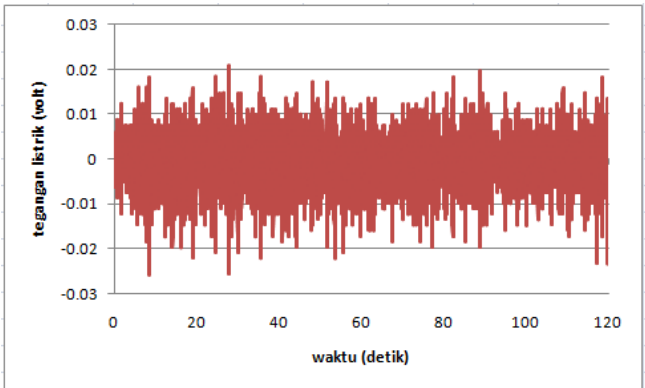

(a)

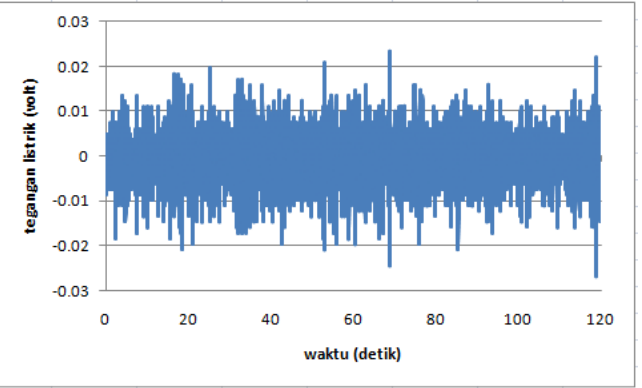

(b)

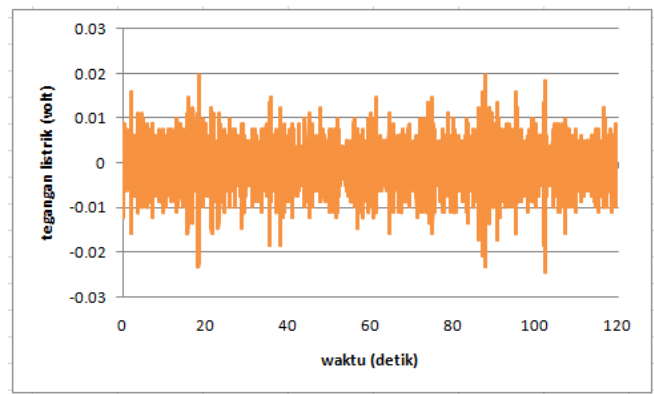

(c)

Gambar 4. Hubungan tegangan listrik dan waktu (a) bluff body segitiga $1 \mathrm{~cm}$, (b) bluff body segitiga $2 \mathrm{~cm}$, (c) bluff body segitiga $3 \mathrm{~cm}$

Pembacaan grafik pada gambar 4 akan lebih jelas dengan adanya pembagian rentang voltase dan jumlah data seperti pada tabel 1 . Tegangan terkecil pada bluff body segitiga $3 \mathrm{~cm}$ dihasilkan pada rentang voltase $-0,01$ volt, 0 volt, dan 0,01 volt. Jika ketiga rentang dijumlahkan, maka akan ada sebanyak 11,755 data atau 97\% dari data keseluruhan. Bluff body segitiga $2 \mathrm{~cm}$ dan $1 \mathrm{~cm}$ berturut-turut menghasilkan voltase pada rentang tersebut sebesar $95 \%$ dan $94,5 \%$. Berdasarkan prosentase tersebut, dapat disimpulkan bahwa piezoelektrik sebagian besar beroperasi pada rentang voltase $-0,01$ sampai dengan 0,01 volt.

Tabel 1. Pengelompokan jumlah data berdasarkan rentang tegangan listrik

\begin{tabular}{lcccccccc}
\hline & \multicolumn{7}{c}{ Jumlah data dengan nilai rentang (n) tegangan listrik } \\
\cline { 2 - 9 } Bluff body & $\boldsymbol{A}$ & $\boldsymbol{B}$ & $\boldsymbol{C}$ & $\boldsymbol{D}$ & $\boldsymbol{E}$ & $\boldsymbol{F}$ & $\boldsymbol{G}$ & $\begin{array}{c}\text { Total } \\
\text { data }\end{array}$ \\
\hline Segitiga 1cm & 18 & 424 & 5103 & 1361 & 4880 & 213 & 1 & 12000 \\
Segitiga 2 cm & 8 & 349 & 5219 & 1453 & 4764 & 203 & 4 & 12000 \\
Segitiga 3 cm & 6 & 155 & 5319 & 1794 & 4642 & 84 & 0 & 12000 \\
Total data & 32 & 928 & 15641 & 4608 & 14286 & 500 & 5 & 36000 \\
\hline Catan. & & & & & & & &
\end{tabular}

$\mathrm{A}=-0.03<\mathrm{n}<-0.02 ; \mathrm{B}=-0.02<\mathrm{n}<-0.01 ; \mathrm{C}=-0.01<\mathrm{n}<0 ; \mathrm{D}=0 ; \mathrm{E}=0<\mathrm{n}<0.01 ; \mathrm{F}=0.01<\mathrm{n}<0.02 ; \mathrm{G}=0.02<\mathrm{n}<0.03$

Pada tabel 1. Notasi A, B, C bernilai voltase negatif dan notasi E, F, G bernilai voltase positif. Jumlah data bernilai voltase negatif lebih banyak daripada voltase positif. Prosentase data dari jumlah A-B-C adalah $46 \%$ dan $41 \%$ untuk E-F-G. Berdasarkan hal itu, dimungkinkan terjadi karena olakan udara yang menumbuk piezoelektrik lebih banyak berasal dari sisi atas segitiga dibandingkan dari sisi bawah. Tumbukan piezoelektrik dari arah atas mengakibatkan piezoelektrik melendut kebawah sehingga nilai tegangannya negatif. Angin menumbuk ujung lancip segitiga menyebabkan olakan udara pada sisi atas lebih banyak. Sedangkan di sisi bawah, olakan sedikit terjadi karena adanya sisi alas yang memanjang dan memungkinkan udara untuk cenderung tidak berolak. Pada penelitian Srikanth et al [9], peletakan bluff body segitiga dengan salah satu ujung lancip sejajar sumbu x, sehingga daerah terjadinya olakan akan berimbang. Pada penelitian ini, peletakan segitiga dengan posisi alas sejajar sumbu x yang mengakibatkan perbedaan daerah olakan. Ilustrasi dari peletakan bluff body ditampilkan pada gambar 5 . 


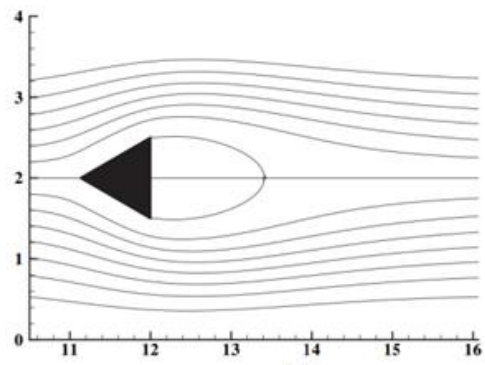

(a)

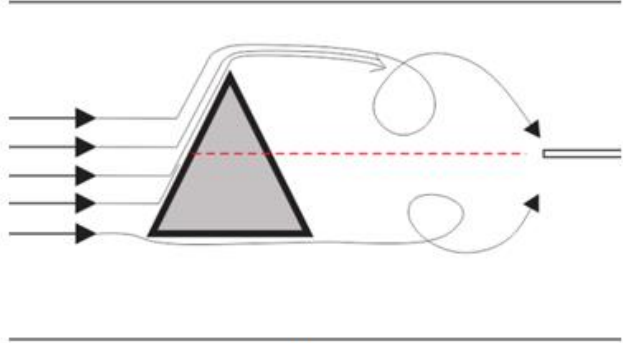

(b)

\section{Gambar 5. Letak dan posisi segitiga (a). Satu sudut lancip sejajar sumbu x [9], (b). Alas sejajar sumbu x}

Gambar 6 menampilkan grafik hubungan antara dimensi bluff body terhadap nilai efektif (Vrms). Ukuran bluff body kecil memiliki nilai efektif tertinggi dan bluff body ukuran besar memiliki nilai efektif terendah. Hal ini disebabkan karena banyaknya olakan udara yang menumbuk permukaan piezoelektrik ketika dilewatkan melalui bluff body segitiga $1 \mathrm{~cm}$. Semakin kecil bluff body yang dilalui oleh udara, maka semakin besar olakan yang terjadi dan menumbuk permukaan piezoelektrik sehingga nilai efektifnya menjadi tinggi.

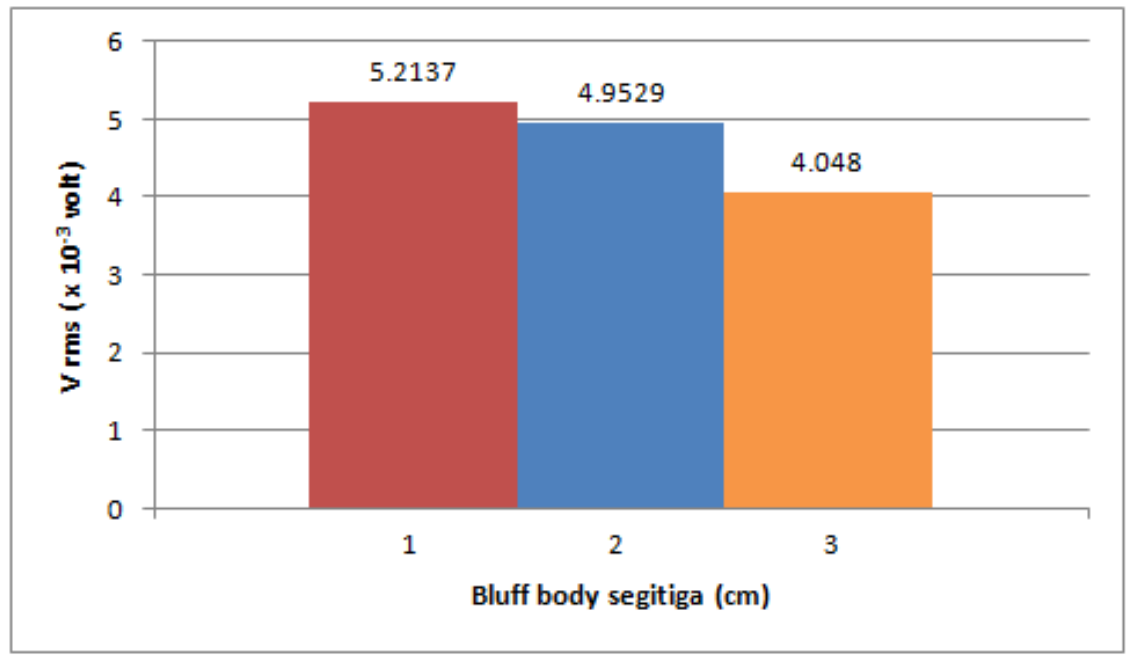

Gambar 6. Grafik hubungan nilai efektif $\left(V_{\text {rms }}\right)$ terhadap bluff body yang dipasang

\section{KESIMPULAN}

Berdasarkan pembahasan pada bab diatas, dapat diambil kesimpulan bahwa semakin kecil ukuran bluff body segitiga, maka akan semakin tinggi nilai efektif yang dihasilkan. Bluff body penampang segitiga $1 \mathrm{~cm}$ memiliki nilai efektif tertinggi yaitu 5,21 x $10^{-3}$ volt. Pada penelitian ini, mayoritas piezoelektrik menghasilkan tegangan listrik pada rentang voltase $-0,01$ hingga 0,01 volt.

\section{UCAPAN TERIMA KASIH}

Ucapan terima kasih disampaikan atas pendanaan penelitian ini kepada DP2M DITJEN RISTEKDIKTI melalui program Penelitian Dosen Pemula (PDP) pelaksanaan tahun 2018.

\section{DAFTAR PUSTAKA}

[1] Nyamayoka LT-E, Adewumi GA, Inambao FL. Design of a prototype generator based on piezoelectric power generation for vibration energy harvesting. J Energy South Africa. 2017;28(4):32-40.

[2] Pawinanto RE, Shumarudin A. Desain Cantilever Beam Piezoelectric Untuk Aplikasi Energi Harvesting. 2016;5(2):5-7.

[3] Rostami AB, Armandei M. Renewable energy harvesting by vortex-induced motions: Review and benchmarking of technologies. Renew Sustain Energy Rev. Elsevier; 2017;70(November):193-214. 
[4] Sirohi J, Mahadik R. Harvesting Wind Energy Using a Galloping Piezoelectric Beam. J Vib Acoust. 2012;134(1):011009.

[5] Sirohi J, Mahadik R. Piezoelectric wind energy harvester for low-power sensors. J Intell Mater Syst Struct. 2011;22(18):2215-28.

[6] Abdelkefi A, Hajj MR, Nayfeh AH. Power harvesting from transverse galloping of square cylinder. Nonlinear Dyn. 2012;70(2):1355-63.

[7] Weinstein LA, Cacan MR, So PM, Wright PK. Vortex shedding induced energy harvesting from piezoelectric materials in heating, ventilation and air conditioning flows. Smart Mater Struct. 2012;21(4).

[8] Gamayel A. Pengaruh Bentuk Bluff Body Terhadap Tegangan Listrik yang Dihasilkan Piezoelektrik dengan Sistem Kantilever. 2017;2(2502):1-5.

[9] Srikanth S, Dhiman AK, Bijjam S. Confined flow and heat transfer across a triangular cylinder in a channel. Int J Therm Sci. 2010;49(11):2191-200. 